\title{
A SELECTION OF TRANSGENIC ANIMAL MODELS USED IN BIOMEDICAL RESEARCH
}

Hussein Ramadan ${ }^{1}$, Kristopher Grohn ${ }^{2}$, Adel Mohamed ${ }^{3}$,

1, 2) Department of Biochemistry, College of Medicine, University of Saskatchewan

3) Department of Anatomy and Cell Biology, College of Medicine, University of Saskatchewan,

Saskatoon, Canada.

\section{ARTICLE INFORMATION:}

\section{Article History}

Received: 2 February 2013

Accepted in revised form: 14 Febru-

ary , 2013

Published: 5 November, 2013

\section{Corresponding author:}

Hussein Ramadan

E-mail: ramadan.hussein@yahoo.com

\section{Keywords:}

Transgenic animal model, stem cell, retroviral vector, DNA microinjection, transgenic mice and human disease.

\begin{abstract}
ABSTRCAT:
The term transgenic animal refers to an animal whose genetic composition has been altered by an addition of foreign DNA. The introduced DNA is called a transgene and the overall process is called transgenic technology. These terms now include the use of living organisms or their parts to make or modify products, to change the characteristics of plants or animals, or to develop micro-organisms for specific uses that currently include several plants and a number of animal species. During the last two decades, transgenic animal model has been an essential mainstay tool in refining our understanding to gene regulation and function of both biological systems and human diseases. The aims of this review article are 1) to elaborate on how transgenic technology is being used to develop the next generation of animal models and 2) to provide an update of the recent advances and a possible structure design for future studies. This review covers the most used animal models of some human disease and specifically discusses two studies conducted on a mouse model of experimental autoimmune encephalomyelitis (EAE) that reproduced specific features of the histopathology and neurobiology of Multiple Sclerosis (MS). This report is presented with the hope to provide both educational and practical basis for the use of these informative animal models.
\end{abstract}

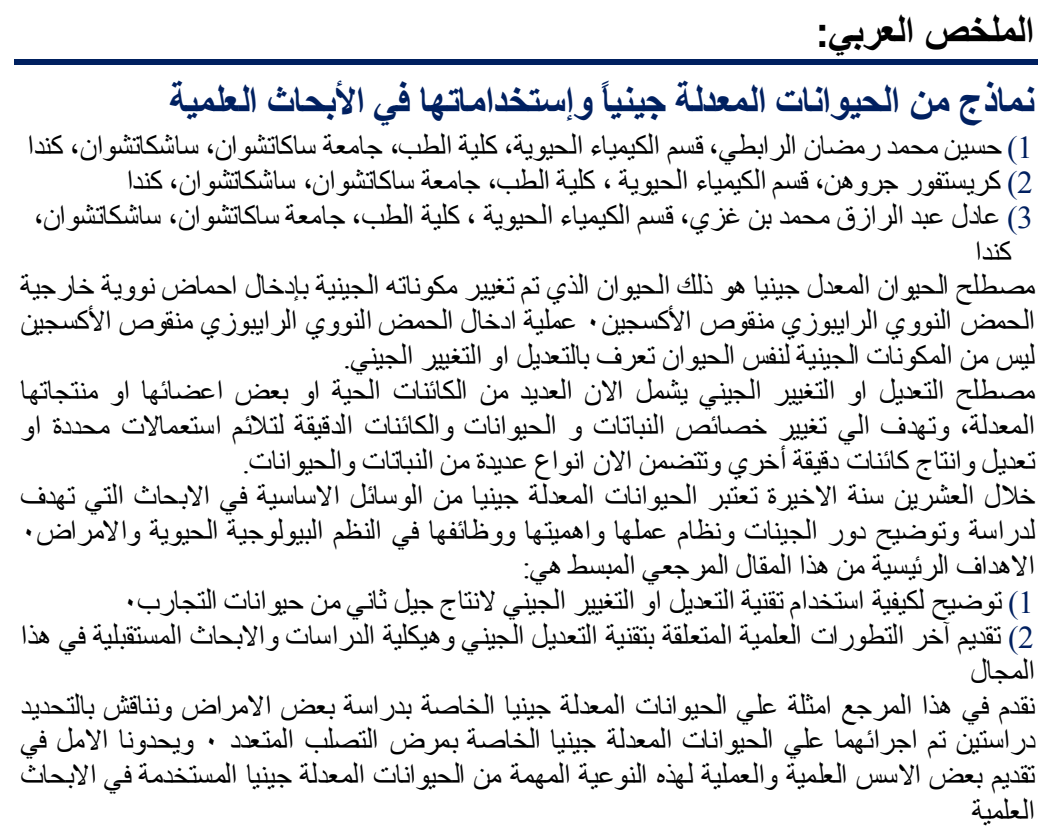


HISTORICAL BACKGROUND:

$\mathbf{O}$ bservation of inherited features and spontaneous mutations were the main mode of studying the regulation and function of mammalian genes. Prehistoric era to Mendel genetic observations, selective breeding was a common practice among farmers for the enhancement of chosen traits, e.g., increased milk production. The chronological historical sequences of the transgenic technique can be summarized as follow:

- 1973, Stanley N. Cohen and Herbert Boyer produced the first GMO that recognized the creation of a functional organism that combined and replicated genetic information from different species ${ }^{1}$.

- 1974, Rudolf Jaenisch successfully managed to insert foreign DNA into the early-stage of mouse embryos; the resulting mice carried the modified gene in all their tissues ${ }^{2}$. Subsequent experiments that lead to injecting leukemia genes to early mouse embryos using a retrovirus vector proved the genes integrated not only to the mice themselves, but also to their progeny". Later, in 1976, Jaenisch developed retrovirusmediated transgenesis ${ }^{4}$ by infecting 4-8 cell mouse embryos with the Moloney leukemia virus and proving the leukimia was passed on through the mouse line following Mendelian inheritance. This indicated that an exogenous virus could become an endogenous virus if it infects cells in the early embryonic stage.

- 1974, Brinster established the first chimeric mice. He and his colleagues discovered that oldercells couldalso takepart in the development of blastocysts they were injected into. Stem cells from donors were combined at an early stage of development (eight cells) to form a single embryo that later developed into a chimeric adult, exhibiting characteristics of each strain $^{5}$.

- 1981, Gordon and Ruddle introduced the DNA microinjection ${ }^{6}$, the first technique that proves to be a successful application in mammals. In addition it was the first technique introduced to mice and subsequently to other species such as rats, rabbits, sheep, pigs, birds, and fish ${ }^{6}$.

- 1986, Gossler et al.developed embryonic stem (ES) cell-mediated gene transfer ${ }^{7}$

\section{METHODSOF INTRODUCINGTHE TRAN- SGENE INTO ANIMALS:}

A. Embryonic Stem Cell approach.

This method involves prior insertion of the desdesired DNA sequence by homologous recom- bination into in vitro culture of embryonic stem (ES) cells.

- ES cellsfrom adonor blastocyst are transfected with the transgene (most likely on a plasmid).

- Transfected EScells are injected into a recipient blastocyst to form a chimera.

- The chimeric blastocyst is placed into the uterus of a surrogate mother.

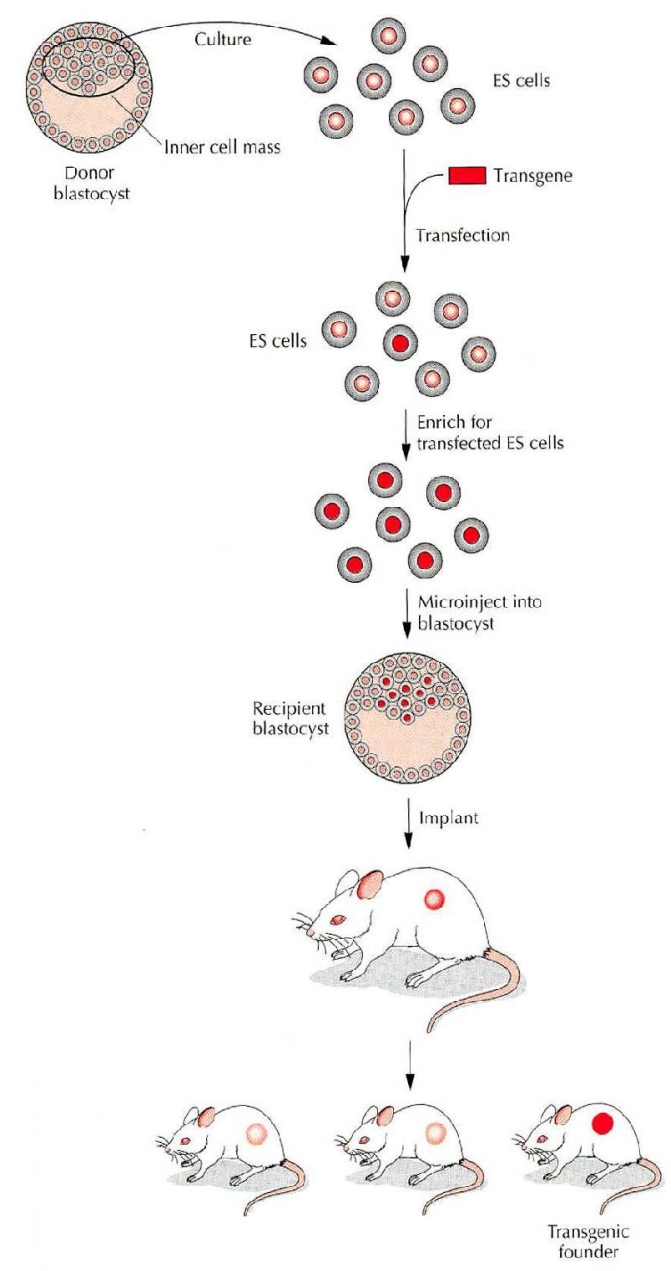

Fig: 1. Embryonic Stem Cell approach ${ }^{8}$.

B. Retroviral vector approach.

Theaimis to increasethe probability of expression; gene transfer is mediated by means of a carrier or vector, usually a virus or a plasmid. Retroviruses are commonly used as vectors to transfer genetic material into the cell, taking advantage of their ability to infect host cells, the technique order as follow:

- Embryos are infected with the retrovirus.

- The retrovirus mediates integration of the transgene into the host genome.

- The modified embryo is placed into the uterus of a surrogate mother. 


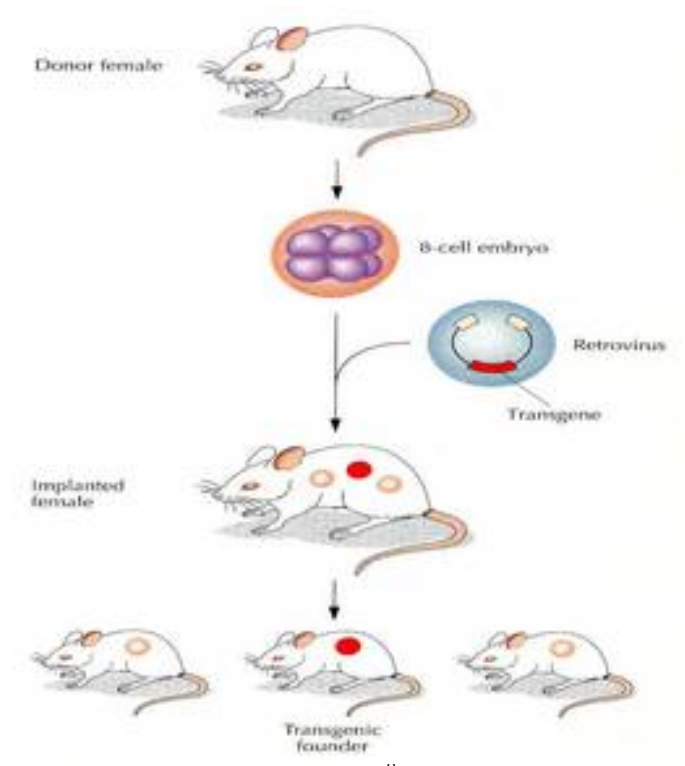

Fig: 2. Retroviral vector approach ${ }^{8}$.

C. DNA Microinjection approach

Thistechnique includes the direct microinjection of a chosen gene construct (a single gene or a combination of genes) from another member of the same species or from a different species, into the pronucleus of a fertilized ovum, the technique order as follow:

- Eggs are fertilized in vitro.

- The transgene carried by a modified retrovirus is microinjected into the male pronucleus.

- The transgene integrates into host chromosome.

- The zygote grows in culture to the blastocyst stage.

- The modified embryo is placed into the uterus of a surrogate mother.

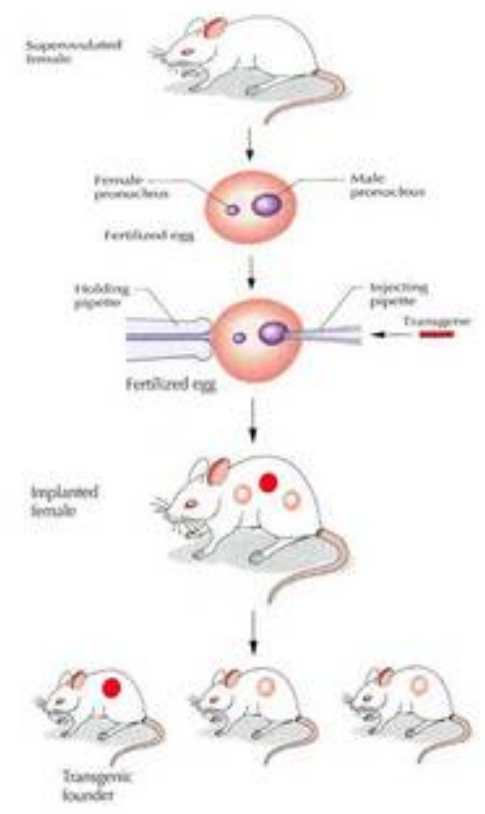

Fig: 3. DNA Microinjection approach ${ }^{8}$.

\section{TRANSGENIC MICE AS MODELS FOR HUMAN DISEASE:}

Animal models areessential part in medical researches that lead to more understanding of human disease processes and, subsequently, the testing of potential therapeutic strategies such as:

A. Transgenic mouse modelsofAlzheimer's disease (AD) ${ }^{9}$

B. Transgenic mouse models of Poliomyelitis ${ }^{10}$, " C. Transgenic mouse models of osteoarthritis (OA). ${ }^{12}$

D. Transgenic mouse models of psychiatric disease. $^{13}$

The full scope of all transgenic models would be too varied to cover in one paper. As such only the 4 mentioned models will be covered in this publication.

\section{A: Alzheimer's disease (AD) models:}

$\mathrm{AD}$ is a progressive neurodegenerative disease. Majority of $\mathrm{AD}$ cases are sporadic; however few show a familial pattern, which might contribute into the disease's origin and mode of action. Transgenic mouse model have been thoroughly investigated the familial forms through overexpressing the mutated alleles of the familial Alzheimer's disease linked genes APP $^{9}$, PSEN1 and PSEN2 ${ }^{49}$. APP, PSEN1, and PSEN2 have over 100 rare and highly penetrant mutations that are implicated in early onset of AD. Alternate modeling studies show that apolipoprotein $\mathrm{E}$ associated with increased susceptibility to $\mathrm{AD}$ in later years ${ }^{21}$. Recent studies suggest that all mutations of these 4 critical $\mathrm{AD}$ linked proteins account for less than $30 \%$ of the genetic component to the disease; worth noting that Mouse models will be critical to the identification of other related genetic factors ${ }^{20}$. The first transgenicAlzheimer's disease models were used the amyloid precursor protein (APP) gene. The resultant APP23 model that first described by Sturchler-Pierrat and colleagues, is a highly valuable, and frequently cited, model of Alzheimer's disease research and neurodegenerative disease in general ${ }^{9}$. This transgenic mouse line was created by expressing APP751 containing common APP mutations found in Alzheimer's patients. The model suggests 4 new pieces of information: 1) early and late onset $\mathrm{AD}$ presentations are distinct from each other, indicating different causes or mechanisms. 2) Age of onset varies within the family.3) Only $1 / 3$ of the theoretical predisposition to $A D$ will become manifest during the lifetime of those at risk. 4) A single dominantgene with a popula- 
tion allele frequency of 0.13 is responsible for the increased susceptibility after the $9^{\text {th }}$ decade of life ${ }^{9}$. These findings represent how useful mouse models can be as a tools for the comparison of dissimilar disease states that may have multiple mechanisms of action. Since the original model in 1997, significant leaps have been made from simply observing the effectsof different mutations to actively trying to manage and treat the effects of $\mathrm{AD}$. A recent study by Sung Ok Yoon and colleagues (2012) ${ }^{21}$ found that, Alzheimer's mice expressing amyloid plaques that mimic aggressive forms of the $\mathrm{AD}$ patients, the elimination of amyloid peptide inducer jnk3 leads to a $90 \%$ reduction in the number of these plaque forming peptides. Further comparison of the brains of $\mathrm{AD}$ patients reveals that a $30-40 \%$ comparative increase in jnk3, suggesting jnk3 as a target in future $A D$ treatment $^{22}$.

\section{B: Poliomyelitis models:}

Poliovirus is a tropic to the nervous system; once the virus infects the nervous system it will cause a neurodegenerative disease called poliomyelitis. This disease is characterized by destruction of motor neurons and eventually leads to skeletal muscle paralysis. Mice are immune to polio infection because they lack the cell surface protein (polio receptor) to which the poliovirus binds ${ }^{10}$. Ruibao Ren and colleagues created a mouse model which could be infected by poliomyelitis by creating a transgenic mouse line that expressed the human polio receptor (PVR) gene ${ }^{11}$. This modified mouse used to generatea mouse model of poliovirus's neurovirulence, attenuation, and tissue tropism, in addition, because the PVR modified mice express the human cell receptor, human specific poliovirus vaccines can be tested in mice, allowing more improvement in vaccine efficiency $^{11}$. The first transgenic mouse models for polio utilized the technique to search for the critical regions influencing infectivity in both the human-mouse receptor, and the genome of the virus itself ${ }^{23}$. Subsequent models, such as Shane Crotty and colleague's mouse model, examined the patterns of infection and severity of effects of poliovirus as well as aggravating factors for the disease from the mice themselves, such as age and method of infection ${ }^{24}$. Recent and likely future models will deal with the use of modified poliovirus and PVR modified mice in order to find therapeutic approaches towards treating tumors and nervous system trophic disorders ${ }^{25}$.

\section{C: Osteoarthritis (OA) models:}

OA is acomplex disease with many contributing factors. OA can result from traumatic insult, congenital or developmental disease, bone and joint diseases, insufficiency of cartilage properties, or neuropathic arthropathy. Due to the differences in animal cartilage, animal studies cannot be comparable to human tissue with any regularity, as even among humans OA occurs due to a variety of stresses and genetic factors. Animal models may be similar in phenotype, but with different underlying conditions contributing compared to human $\mathrm{OA}^{26}$. Transgenic mice, expressing genes associated with development of OA in humans, share more promise in creating relevant animal models in these scenarios $^{12}$. Researchers investigated the use of the spontaneous mutations which occur naturally in several mouse strains to define regions of interest. Strains with mutations in cartilage collagen types II and IX develop early onset $\mathrm{OA}^{27}$. These non-transgenic mice make promising modelsof age related OA. Unfortunately, they often show signs of chondrodysplasia, experiencing abnormal bone growth where fibrous bone tissue replaces normal bone tissue ${ }^{28}$. Their heterogeneous offspring are more typical but still show the early-onset OA phenotype, making them useful for isolating defined mutations that act as predisposing factors to $\mathrm{OA}^{12}$. The OA phenotype has been linked to mutations affecting the different types of collagens, but the regulation and expression of type II, IX, and XI collagens in relation to OA is poorly understood ${ }^{29}$; Transgenic animal models offer an opportunity for more in depth studies of these human collagen mutations. The human transgenes Col2al, Col9a1, Col11a1 have high homology, and are indicated as being related to the regulation of CII, CIX, and $\mathrm{CXI}^{29}$. Deletions and substitutions of critical regions of Col2al in transgenic mice leads to phenotypes resembling chondrodysplasia $^{12}$; increasing expression rate of typical Col2al that lead to OA, as the fibril assembly of the collagen is disrupted from irregular expression $^{30}$. Type IX collagens are heterodimers consisting of three polypeptide chains, which covalently bind to the surface of type II collagen and anchor them to the surrounding matrix. Truncation of these chains leads to mild chondrodysplasia, and progressive $\mathrm{OA}$ in mice. Young mice are phenotypically normal, but experience severe spinal degradation from 6 months of age and onward ${ }^{31}$. Disturbances in Col11a proteins related to XI collagen have variable effects on the susceptibility of mice to 
OA. Targeted disruption of Col11A2 does not cause the pronounced OA phenotype seen by disruption of Col11A1, but it does produce a milder effect after 1 year of age, implicating CXI disruption in late onset $\mathrm{OA}^{32}$.

\section{D: Psychiatric disease models:}

Genetic susceptibility to common psychiatric disease arises from the complex interactions between multitudes of genes; these diseases also have a strong environmental component. While it is unlikely that transgenic mice will show complex disorders such as schizophrenia, obsessive compulsive disorders, or autism due to their complex sociological and cultural components ${ }^{13}$. Mouse models can be extremely effective in separating the specific roles of genes, neural pathways, neuron subtypes, and brain regions in specific states of abnormal behaviour. Numerous mouse models of psychiatric disorders have already been generated ${ }^{13}$. Such models cover ranges of abnormal behaviour, such associal anxiety, unbalanced mood swings, psychomotor agitation, and learning/memory impairment ${ }^{13},{ }^{33,34}$. Many well categorized psychiatric disorders such as Autism, Schizophrenia, mental depression, and Attention deficit hyperactivity disorder, while extremely complex and affected heavily by human cognition and culture, share physiological traits which can be used to approximate these disorders in animal models ${ }^{13}$. Neuroanatomy findings in schizophrenia are classic hallmarks of the disorder and manifestas larger brain volume/weight and decreased concentration of purkinje cells in the human cerebellum, this reduced cerebellar size also occurs in mice ${ }^{35}$. These intermediate traits can be used in transgenic animal studies to characterise genes which may be associated with phenotypes associated with mental illness. Following the previous theme of schizophrenia, experiments in transgenic mice carrying a gene known as disrupted-in-schizophrenia-1 (DISC1) ${ }^{33}$ found that the mice have enlarged lateral ventricles on their left side of their brains, which suggests a link to the asymmetrical change in neuroanatomy found in human schizophrenia patients. Bipolar disorder is another mental disorder characterised by periods of mania or depression in individuals with otherwise normal moods $^{36}$. The DSM classifies Bipolar disorder based on clinical presentation, Bipolar I characterized by the occurrence of one or more manic or mixed episodes and Bipolar II by at least one hypomanic or major depressive episode ${ }^{37}$. Considering both classes of the disease, the world prevalence of Bipolar disorder is about 3.5\% ${ }^{13}$. Animal models are commonly utilized to investigate the effectiveness of lithium and other mood stabilizers and determine their mechanism of action ${ }^{38}$.

\section{ASIDE:}

Transgenic mouse research has led to major advances in the ability to treat a number of diseases. For example, work on mice resulted in successful therapies of acute promyelocytic leukaemia (APL) ${ }^{14}$, a cancer that was previously untreatable. Disease models such as the Alzheimer's Mouse, the Oncomouse, and the AIDs mouse are critical laboratory models for developing treatments for these specific diseases and cancer studies ${ }^{15}$.

\section{TRANSGENIC MICE AS A MODELS OF MULTIPLESCLEROSIS DISEASE- EXAMPLES FROM OUR RESEARCH.}

1) Multiple sclerosis - Study1

Axonal damage, demyelination and inflammation of the central nervous system are the major pathological features of the human multiple sclerosis (MS). In our experiment we used the Experimental autoimmune encephalomyelitis (EAE) animal model that mimics human MS and tested the effect of Thymoquinone (TQ) ${ }^{16}$, an oil constituent of Nigella Sativa also known as black seed. Thymoquinone (TQ) has shown advantageous immunomodulatory properties amplifying the T-cell immune responses ${ }^{41,40}$. TQ, an oil extract from the seeds of Nigella Sativa, has many pharmacological and toxicological properties ${ }^{39}$. Studies have shown TQ to have anti-inflammatory, analgesic, antipyretic, antimicrobial,and anti-neoplastic activity $39,43,40,30$ female mice strain C57BL/6J of age between 6 to 12 weeks and weight between $20-22 \mathrm{gms}$ were divided into 3 groups 10 mice each. Group $\mathrm{A}, \mathrm{B}$ and $\mathrm{C}$, all received $100 \mu \mathrm{g}$ MOG (SC) to induce EAE. Group A used as a control animal models of EAE for the acute and relapsing stages respectively. Acute phase ran for 28 days post $\mathrm{EAE}$ induction while the chronic phase ran for 50 days post EAE induction. Group B, received MOG (SC) and TQ (IP) from day 1 till day 50, while group $\mathrm{C}$, received MOG (SC) and then TQ (IP) on the appearance of first sign and symptoms of CR-EAE. TQ was given for 5 consecutive days to treat the CR-EAE. Preliminary result showed that TQ, due to its antioxidant effect, is almost $90 \%$ preventive and $50 \%$ curative in CR-EAE ${ }^{16}$.

2) Multiple sclerosis - Study 2 
Genome-wide association studies suggest a connection between genes encoding IL-7R and IL-7 to MS ${ }^{17}$. This study was conducted to elucidate the role of IL-7 and IL-7R genes in the pathogenesis and progression of MS by determining gene expression in experimental autoimmune encephalomyelitis (EAE) C57BL/6J mice and Lewis rats. Genetic linkage, candidate gene association, and gene expression studies have been conducted to identify genes linked to MS. Two genes suggested to be associated with MS with some consistency are the interleukin-7 (IL-7) gene and interleukin-7 receptor (IL-7R) gene. IL-7, a key pleiotropic cytokine, stimulates differentiation and proliferation required for normal B and T cell development ${ }^{44}$. IL-7 is known to exert growth promoting and antiapoptotic effects on T-cells and has been shown to enhance the T-cell mediated response to myelin proteins ${ }^{45,46}$. Additionally, IL-7 may have a role in the inflammatory response by continually activating T-cells to secrete proinflammatorycytokines ${ }^{47}$. 30 female C57BL/6 J mice separated into 3 equal groups (A, B, and C). The mice were subcutaneously injected with $\mathrm{MOG}^{48}$ peptideemulsified in Complete Freund's adjuvant (CFA). All mice were sacrificed 50 days after induction of EAE. Blood samples were obtained. Brain and spinal cord tissue was stored at $-80^{\circ} \mathbf{C}$. Group A was the control group for acute and chronic relapsing stages of EAE. Group B received intraperitoneal injections of thymoquinone for 50 days following EAE induction. Group $\mathrm{C}$ received intraperitoneal injections of thymoquinone after the first appearance of chronic symptoms. Lewis Rat brain and spinal cord frozen at $-80^{\circ} \mathrm{C}$ was obtained for genetic analysis. Group A was induced with EAE but had no anti-oxidant treatment. Group B was induced with EAE and had anti-oxidant treatment of BHA. The genetic control was not induced with EAE and had no anti-oxidant treatment. A significant increase of glutathione was observed in mice with reduced symptoms, likely due to TQ anti-oxidant activity. Gene expression studies remain elusive but point towards the involvement of IL-7R in the progression and pathogenesis of EAE.

\section{CONCLUSION:}

It is well known that animal models are extensively used in research filed. In recent years, transgenic mouse models have become crucial tools in human disease research. The application of transgenic animals continuously proves to be one of the most valuable techniques in understanding disease mechanisms; they provide comparable subjects to distinguish the effects of genetic and environmental factors on pathogenesis, understanding the role of complex interactions of molecular and cellular processes and mechanisms on the disease progres$\operatorname{sion}^{18}$. Scientists have developed numerous methods relating to the transgenic animal models; in addition, they established more emphasis in minimizing animal suffering while achieving the utmost benefits to medicine ${ }^{19}$.

\section{ACKNOWLEDGEMENT:}

Multiple sclerosis studies mentioned in this review have been done in collaboration and supervision of Professor Adel Mohamed, Anatomy and Cell Biology department at University of Saskatchewan, Canada.

\section{REFERENCES:}

1) Cohen, S. N., Chang, A. C., and Hsu, L. (1972) Nonchromosomal antibiotic resistance in bacteria: genetic transformation of Escherichia coli by R-factor DNA, Proceedings of the National Academy of Sciences of the United States of America 69, 2110-2114.

2) Jaenisch, R., and Mintz, B. (1974) Simian virus 40 DNA sequences in DNA of healthy adult mice derived from preimplantation blastocysts injected with viral DNA, Proceedings of the National Academy of Sciences of the United States of America 71, 1250-1254.

3) Jaenisch, R. (1975) Infection of mouse blastocysts with SV40 DNA: normal development of the infected embryos and persistence of SV40-specific DNA sequences in the adult animals, Cold Spring Harbor symposia on quantitative biology $39 \mathrm{Pt}$ 1, 375-380.

4) Jaenisch, R. (1976) Germ line integration and Mendelian transmission of the exogenous Moloney leukemia virus, Proceedings of the National Academy of Sciences of the United States of America 73, 1260-1264.

5) Brinster, R. L. (1974) The effect of cells transferred into the mouse blastocyst on subsequent development, The Journal of experimental medicine 140, 1049-1056.

6) Gordon, J. W., and Ruddle, F. H. (1981) Integration and stable germ line transmission of genes injected into mouse pronuclei, Science 214, 1244-1246.

7) Gossler, A., Doetschman, T., Korn, R., Serfling, E., and Kemler, R. (1986) Transgenesis by means of blastocyst-derived embryonic stem cell lines, Proceedings of the National Academy 


\section{Hussein Ramadan et al}

of Sciences of the United States of America 83, 9065-9069.

8) Pasternak, J. (2010) - Molecular biotechnology textbook 4th , (275-280).

9) Sturchler-Pierrat, C., Abramowski, D., Duke, M., Wiederhold, K. H., Mistl, C., Rothacher, S., Ledermann, B., Burki, K., Frey, P., Paganetti, P. A., Waridel, C., Calhoun, M. E., Jucker, M., Probst, A., Staufenbiel, M., and Sommer, B. (1997) Two amyloid precursor protein transgenic mouse models with Alzheimer disease-like pathology, Proceedings of the National Academy of Sciences of the United States of America 94, 13287-13292.

10) Koike, S., Taya, C., Kurata, T., Abe, S., Ise, I., Yonekawa, H., and Nomoto, A. (1991) Transgenic mice susceptible to poliovirus, Proceedings of the National Academy of Sciences of the United States of America 88, 951-955.

11) Ren, R. B., Costantini, F., Gorgacz, E. J., Lee, J. J., and Racaniello, V. R. (1990) Transgenic mice expressing a human poliovirus receptor: a new model for poliomyelitis, Cell 63, 353-362.

12) Helminen, H. J., Saamanen, A. M., Salminen, H., and Hyttinen, M. M. (2002) Transgenic mouse models for studying the role of cartilage macromolecules in osteoarthritis, Rheumatology (Oxford) 41, 848-856.

13) Seong, E., Seasholtz, A. F., and Burmeister, M. (2002) Mouse models for psychiatric disorders, Trends in genetics : TIG 18, 643-650.

14) - Pollock, J. L., Westervelt, P., Walter, M. J., Lane, A. A., and Ley, T. J. (2001) Mouse models of acute promyelocytic leukemia, Current opinion in hematology 8, 206-211.

15) Van Dam, D., Vloeberghs, E., Abramowski, D., Staufenbiel, M., and De Deyn, P. P. (2005) APP23 mice as a model of Alzheimer's disease: an example of a transgenic approach to modeling a CNS disorder, CNS spectrums 10, 207222.

16) Mohamed, A., Waris, H. M., Ramadan, H., Quereshi, M., and Kalra, J. (2009) Amelioration of chronic relapsing experimental autoimmune encephalomyelitis (cr-eae) using thymoquinone 17) biomed 2009, Biomedical sciences instrumentation 45, 274-279.

18) Spate, S., Ramadan, H. H., and Mohamed, A. (2010) Interleukins (IL-7 and IL-7r) gene expression and thymoquinones role in the amelioration of eae symptoms - biomed 2010, Biomedical sciences instrumentation 46, 190-185. 19) Federation of European Laboratory Animal Science Associations (FELASA) September
(1992) Transgenic Animals - Derivation, Welfare, Use and Protection.

20) Moore, C. J., and Mepham, T. B. (1995) Transgenesis and animal welfare, Alternatives to laboratory animals : ATLA 23, 380-397.

21) Tanzi, R. E., and Bertram, L. (2001) New frontiers in Alzheimer's disease genetics, Neuron 32, 181-184.

22) Corder, E. H., Saunders, A. M., Strittmatter, W. J., Schmechel, D. E., Gaskell, P. C., Small, G. W., Roses, A. D., Haines, J. L., and PericakVance, M. A. (1993) Gene dose of apolipoprotein E type 4 allele and the risk of Alzheimer's disease in late onset families, Science 261, 921923.

23) Yoon, S. O., Park, D. J., Ryu, J. C., Ozer, H. G., Tep, C., Shin, Y. J., Lim, T. H., Pastorino, L., Kunwar, A. J., Walton, J. C., Nagahara, A. H., Lu, K. P., Nelson, R. J., Tuszynski, M. H., and Huang, K. (2012) JNK3 perpetuates metabolic stress induced by Abeta peptides, Neuron 75, 824-837.

24) La Monica, N., Almond, J. W., and Racaniello, V. R. (1987) A mouse model for poliovirus neurovirulence identifies mutations that attenuate the virus for humans, Journal of virology 61, 2917-2920

25) Crotty, S., Hix, L., Sigal, L. J., and Andino, R. (2002) Poliovirus pathogenesis in a new poliovirus receptor transgenic mouse model: agedependent paralysis and a mucosal route of infection, The Journal of general virology 83, 1707-1720.

26) Toyoda, H., Yin, J., Mueller, S., Wimmer, E., and Cello, J. (2007) Oncolytic treatment and cure of neuroblastoma by a novel attenuated poliovirus in a novel poliovirus-susceptible animal model, Cancer research 67, 2857-2864.

27) Billingham MEJ. (1998) Advantages afforded by the use of animal models for evaluation of potential disease $\square$ modifying osteoarthritis drugs (DMOADs). In: Brandt KE, Doherty M, Lohmander LS, eds. Osteoarthritis. Oxford: Oxford University Press, 429-38.

28) Doherty NS, Griffiths RJ, Pettipher ER. (1998) The role of animal models in the discovery of novel disease $\square$ modifying osteoarthritis drugs (DMOADs). In: Brandt KE, Doherty M, Lohmander LS, eds. Osteoarthritis. Oxford: Oxford University Press, 439-49.

29) Li, Y., and Olsen, B. R. (1997) Murine models of human genetic skeletal disorders, Matrix biology : journal of the International Society for Matrix Biology 16, 49-52.

30) Bridgewater, L. C., Lefebvre, V., and de Crombrugghe, B. (1998) Chondrocyte-specific 
enhancer elements in the Col11a2 gene resemble the Col2al tissue-specific enhancer, The Journal of biological chemistry 273, 1499815006.

31) Garofalo, S., Metsaranta, M., Ellard, J., Smith, C., Horton, W., Vuorio, E., and de Crombrugghe, B. (1993) Assembly of cartilage collagen fibrils is disrupted by overexpression of normal type II collagen in transgenic mice. Proc Natl Acad Sci USA3825-9

32) Nakata, K., Ono, K., Miyazaki, J., Olsen, B. R., Muragaki, Y., Adachi, E., Yamamura, K., and Kimura, T. (1993) Osteoarthritis associated with mild chondrodysplasia in transgenic mice expressing alpha 1(IX) collagen chains with a central deletion, Proceedings of the National Academy of Sciences of the United States of America 90, 2870-2874.

33) Li, S. W., Takanosu, M., Arita, M., Bao, Y., Ren, Z. X., Maier, A., Prockop, D. J., and Mayne, R. (2001) Targeted disruption of Col11a2 produces a mild cartilage phenotype in transgenic mice: comparison with the human disorder otospondylomegaepiphyseal dysplasia (OSMED), Developmental dynamics : an official publication of the American Association of Anatomists 222, 141-152.

34) Pobbe, R. L., Defensor, E. B., Pearson, B. L., Bolivar, V. J., Blanchard, D. C., and Blanchard, R. J. (2011) General and social anxiety in the BTBR $\mathrm{T}+\mathrm{tf} / \mathrm{J}$ mouse strain, Behavioural brain research 216, 446-451.

35) Gould, T. D., and Einat, H. (2007) Animal models of bipolar disorder and mood stabilizer efficacy: a critical need for improvement, Neuroscience and biobehavioral reviews 31, 825831.

36) J.N. Crawley. (2000) What's Wrong with my Mouse? John Wiley \& Sons

37) Todd D. Gould, Haim Einat. (2007)Animal Models of Bipolar Disorder and Mood Stabilizer Efficacy. Neurosci Biobehav Rev. 31(6): 825-831.

38) American Psychiatric Association. (2000). Diagnostic and statistical manual of mental disorders (4th ed., text rev.). Washington, DC: Author

39) O'Donnell, K. C., and Gould, T. D. (2007) The behavioral actions of lithium in rodent models: leads to develop novel therapeutics, Neuroscience and biobehavioral reviews 31, 932-962.

40) Ali, B., \& Blunden, G. (2003). Pharmacological and toxicological properties of Nigella sativa. Phytotherapy Research , 17 (4), 299-305.
41) Salem, M. (2005). Immunomodulatory and therapeutic properties of the Nigella sativa L. seed. International immunopharmacology , 5 (13-14), 1749-1770.

42) Jones, M., Nguyen, T., DeBoy, C., Griffin, J., Whartenby, K., Kerr, D., et al. (2008). Behavioral and pathological outcomes in MOG 35-55 experimental autoimmune encephalomyelitis. Journal of Neuroimmunology , 199, 83-93.

43) Hajhashemi, V., Ghannadi, A., \& Jafarabadi, H. (2004). Black cumin seed

essential oil, as a potent analgesic and antiinflammatory drug. Phytotherapy Research , 18 (3), 195-199.

44) Kikuchi, K., Kasai, H., Watanabe, A., Lai, A. Y., \& Kondo, M. (2008). IL-7 specifies B cell fate at the common lymphoid progenitor to pre-proB transition stage by maintaining early $\mathrm{B}$ cell factor expression. The Journal of Immunology , 181, 383-392.

45) Booth, D., Arthur, A., Teutsch, S., Bye, C., Rubio, J., Armati, P., et al. (2005). Gene Expression and genotyping studies implicate the interleukin 7 receptor in the pathogenesis of primary progressive multiple sclerosis. Journal of Molecular Medicine 83, 822-830.

46) Traggiai, E., Biagioli, T., Rosati, E., Ballerini, C., Mazzanti, B., Ben Nun, A., et al. (2001). IL-7-enhanced T-cell response to myelin proteins in multiple sclerosis.

Journal of Neuroimmunology , 121, 111-119.

47) Van Roon, J., Glaudemans, K., Bijlsma, J., \& Lafeber, F. (2003). Interleukin 7

stimulates tumor necrosis factor $\alpha$ and Th1 cytokine production in joints of patients with rheumatoid arthritis . EULAR , 62, 113-119.

48) Jones, M., Nguyen, T., DeBoy, C., Griffin, J., Whartenby, K., Kerr, D., et al.

(2008). Behavioral and pathological outcomes in MOG 35-55 experimental autoimmune encephalomyelitis. Journal of Neuroimencephalogy , 199, 83-93.

49) Zhang, X., Garbett, K., Veeraraghavalu, K., Wilburn, B., Gilmore, R., Mirnics, K., and Sisodia, S. S. (2012) A role for presenilins in autophagy revisited: normal acidification of lysosomes in cells lacking PSEN1 and PSEN2, The Journal of neuroscience : the official journal of the Society for Neuroscience 32, 86338648 . 